\title{
LA INVESTIGACIÓ SOBRE LA PROMOCIÓ DE LA LECTURA EN LA 2.0. ANÀLISI DE CASOS
}

\section{RESEARCH INTO THE PROMOTION OF READING IN 2.0. CASE STUDIES}

\author{
Maite Monar van Vliet \& Gemma Lluch \\ Universitat de València \\ maitemvv@gmail.com / gemma.lluch@uv.es
}

Resum: L'article presenta l'estudi de tres casos, experiències reals de promoció de la lectura amb l'ús de tecnologia virtual en centres escolars valencians durant tot el curs 20IO-20Ir. La metodologia utilitzada segueix un enfocament bàsicament qualitatiu i secundàriament d'investigacióacció, ja que les dades resultants han estat utilitzades pels mediadors per millorar-ne la pràctica. Concretament, l'estudi dels tres casos es fa des de l'observació participant per a la recollida de dades que es completa amb l'entrevista, les històries de vida, el relat de vida i el qüestionari. Finalment, s'hi aplica el grup de discussió per a l'anàlisi i la interpretació i la triangulació com a mètode d'avaluació.

Paraules clau: lectura i Web 2.0, investigació qualitativa, estudi de casos.

Abstract: The article presents three case studies of reading promotion by using virtual technology in some Valencian schools, throughout the 20IO-20II academic year. The methodology is mainly qualitative, supplemented by investigation-action, since the resulting data have been used by mediators to improve their practice. Specifically, the study of the three cases has been carried out through participative observation in order to collect data. The process was then was completed with interviews, life stories and a questionnaire. Lastly, a discussion group contributed to the analysis, interpretation and triangulation as a method of evaluation.

Key words: reading and Web 2.o, qualitative research, case studies. 
En els últims anys una part dels docents de l'educació secundària ha dissenyat i executat un nombre significatiu d'accions per promocionar la lectura al centre escolar amb el suport d'eines i plataformes virtuals de la web social. Les iniciatives es realitzen amb textos literaris i paraliteraris, és a dir, amb la lectura canònica i amb l'anomenada pel currículum lectura per plaer, i barregen lectura i escriptura de textos escrits i audiovisuals. En definitiva, cerquen acomplir els objectius del currículum (veg. Decret II2/2007, DOCV núm. 5562, p. 3042I) següents: l'article «I4. Comprendre textos literaris utilitzant els coneixements sobre les convencions de cada gènere, els temes i motius de la tradició literària i els recursos estilístics. Apreciar-ne les possibilitats comunicatives per a la millora de la producció personal»; el «I6. Conéixer i distingir les principals èpoques artístiques i literàries, els seus trets característics, les obres, i les autores i els autors més representatius de cada època. Conéixer les obres i els fragments representatius de les literatures de les llengües oficials de la Comunitat Valenciana»; i el «I7. Interpretar i utilitzar la lectura i l'escriptura com a fonts de plaer, d'enriquiment personal i de coneixement del món, i consolidar hàbits lectors per mitjà de textos adequats a l'edat.»

Tot i la importància que aquestes pràctiques tenen, hi ha poques investigacions que permeten conèixer-les i avaluar-les. Aquest article mostra l'estudi de tres casos: tres experiències reals de promoció de la lectura amb l'ús de les tecnologies en centres escolars valencians durant el curs 20IO-20II. La metodologia utilitzada, descrita en els treballs de Monar (2012b) i Lluch (2013), segueix un enfocament bàsicament qualitatiu i secundàriament d'investigació-acció, ja que les dades resultants han estat utilitzades pels mediadors, els docents, per millorar-ne la pràctica. Concretament, per a l'estudi de tres casos, s'hi utilitza l'observació participant que es completa amb l'entrevista, les històries de vida, el relat de vida i el qüestionari. Finalment, s'hi aplica el grup de discussió per a l'anàlisi i la interpretació i la triangulació com a mètode d'avaluació.

\section{L'ESTUDI DE TRES CASOS}

L'estudi de casos en la investigació sondeja en profunditat i analitza exhaustivament els fenòmens múltiples que constitueixen el cicle de vida d'una pràctica concreta, amb la idea d'establir generalitzacions sobre una població més àmplia a la qual pertany. Per a Coller (2005: 2I-5I) és un mètode que permet la investigació exploratòria i qualitativa, analítica i quantitativa o la combinació d'ambdós, d'altres de tipus històric centrats en processos socials o sincrònics en l'anàlisi d'objectes. 
En el cas concret de la investigació sobre lectura que descrivim, l'orientació és exploratòria, qualitativa i analítica, se centra en un procés social com és l'evolució d'una petita comunitat formada per uns estudiants i un docent. Té un abast d'estudi genèric perquè il.lustra una característica que es troba en altres casos, un procés de lectura (i escriptura) en el marc escolar. A més, els casos analitzats són un exemple il.lustratiu d'un fenomen social contemporani com la comunicació virtual i, a més, esbrinen el funcionament del tractament de la lectura a partir de plataformes virtuals 2.o. La investigació ha optat pels casos múltiples perquè permet analitzar-ne tres de paral.lels i comparar-ne les conclusions.

Els tres casos se centren en les activitats de lectures i escriptures realitzades a l'aula mitjançant la web social. El primer cas és una classe de 4t d'ESO de l'IES Joanot Martorell situat a la ciutat de València, amb la participació en aquest projecte del professor Antoni de la Torre i del seu wiki Portfoli 4. El segon cas és la classe de $2 \mathrm{n}$ d'ESO A del Colegio Helios a l'Eliana, amb l'ajuda del professor Evaristo Romaguera i el seu blog d'aula Somos. Finalment, se sumen a la investigació els alumnes de Gè de primària de l'Escola Gavina de Picanya, amb Albert Dasí i el web Escola Gavina. Els tres casos escollits suposen l'anàlisi de pràctiques lectores dissenyades i proposades per professors de llengua i literatura en un centre educatiu públic, un de privat i l'altre concertat, en tres nivells diferents ubicats en l'acabament d'una etapa educativa. Aquesta diversitat i heterogeneïtat quant a espais, grups, edats i plataformes digitals resulta molt il.lustrativa i permet l'extrapolació d'aquestes pràctiques a altres realitats educatives.

És important subratllar les característiques dels contextos analitzats. Hi participen tres centres escolars valencians, situats a la mateixa ciutat o a les rodalies, i la distància que hi ha entre els tres és de menys de vint-i-dos quilòmetres. Les preocupacions comunes dels professors que hi treballen són la promoció de la lectura i l'ús de la biblioteca escolar, com ho demostra l'intent o la posada en marxa de projectes de promoció lectora, com ara el Seminari de Pla de lectura i biblioteca i el club de lectura i l'ús de les tecnologies a l'aula des dels anys 2005 i 2006.

El grup de treball d'aquest estudi està format per dos participants externs i tres interns. La investigadora externa I desenvolupa funcions d'observació del treball de camp, moderadora i assistent del grup de discussió; la investigadora 2 guia la investigació i observa el grup de discussió. Els participants interns s'estructuren en quatre grups: el primer, format pels tres professors amb funcions de mediadors i membres participants del grup de discussió; el segon, els alumnes triats per a les històries i els relats de vida; el tercer grup el formen la totalitat d'alumnes dels grups participants, i el darrer, la comunitat educativa dels tres centres escolars. 


\section{LA METODOLOGIA DE LA INVESTIGACIÓ}

El punt de partida metodològic triat ha estat l'enfocament qualitatiu, seguint Vasilachis (2006: 24), ja que la intenció d'aquesta investigació és la realització d'una recerca oberta i flexible dirigida a l'obtenció d'informació sobre promoció de la lectura amb l'ús de tecnologies i centrada en la pràctica real a l'aula. L'enfocament es complementa amb una tècnica quantitativa, el qüestionari.

A partir de la proposta d'Olaz (2008: I4) de complementarietat dels enfocaments qualitatiu i quantitatiu i dels suggeriments de combinació d'aquests plantejaments de Blaxter, Hughes \& Tight (2008: 100), la investigació es decanta pel primer tipus de combinatòria: la lògica de la triangulació, on les troballes del qüestionari confronten amb els derivats de les tècniques qualitatives com les històries i els relats de vida, i també pel tercer, on la investigació quantitativa en facilita la qualitativa. El qüestionari proporciona informació de l'alumnat i ajuda a conèixer els subjectes que participen al treball de camp.

L'estudi de casos, l'observació, el grup de discussió i la triangulació faciliten les dades per a l'anàlisi i la interpretació. L'elecció de casos múltiple (Vasilachis 2006: 226) permet partir de diferents instàncies de comparació, tres classes de centres escolars, i disposar de resultats empírics més exhaustius, ja que els casos triats es complementen i són fenòmens similars però en contextos socials i nivells educatius diferents. A partir de la proposta de reagrupació de Callejo (200I) principalment, s'hi utilitza el grup de discussió. Aquesta pràctica d'investigació s'adapta al treball de camp plantejat i disposa d'una moderadora, una assistent i tres participants (els professors) que interrelacionen cara a cara en un temps i un lloc concret periòdicament.

Tant la proposta de Vasilachis (2006:228) del'estudi de casos, com la de Berganza \& Ruiz (2005:267) del grup de discussió coincideixen en la proposta de la triangulació com a validació de les dues metodologies. Vasilachis considera fonamental, en l'estudi de casos, la selecció i l'ús de la triangulació. Berganza \& Ruiz subratlla que el grup de discussió facilita les evidències que obren pas a la possibilitat de triangulació com a generador de noves hipòtesis o com a element de contrast dels resultats obtinguts. La triangulació triada, com indica Berganza \& Ruiz (2005: 40), és la d'informació, ja que es parteix de tres fonts diferents de dades al treball de camp: professorat, alumnat i observadora. Seguint els diferents nivells que exposa Rodríguez Ruiz (2005), en la triangulació d'informació triem l'anàlisi interactiva a partir de les xarxes existents entre individus i grups. No obstant això, també hi és present la triangulació metodològica, recomanada per 
McKernan (I999: 205-209), perquè s'hi organitzen diferents tipus de dades en un marc de referència. Per tant, ha estat una triangulació bàsicament intramètodes.

Com a enfocaments secundaris, s'opta per la investigació-acció i l'etnografia, necessàriament adaptats a la situació de la investigació. Segons Latorre (2003), a la investigació-acció educativa el professorat ha d'aconseguir estudiar, comprendre i transformar la pràctica educativa de la millor manera possible, millorant-la i innovant-la. Aquest treball adapta la proposta i reflexiona sobre les pràctiques a l'aula a partir de la participació del mediador, ja que el professorat no és l'investigador directe, sinó l'observador-mediador de les aportacions que són interpretades per la investigadora.

Vasilachis (2006: II3) descriu l'etnografia com una metodologia que es desenvolupa en l'observació participant. Concretament, en aquesta investigació s'utilitza l'anomenada etnografia escolar que, segons Buendía, Colás \& Hernández (I998: 259-260), pretén descriure, explicar i interpretar la cultura de l'escola i focalitza sobre processos de canvi i innovació a les aules, i l'etnografia virtual que planteja Hine (2004), una metodologia que desenvolupa una comprensió profunda a través de la participació i l'observació, amb l'aplicació directa de determinades tècniques aplicades al món del ciberespai. En efecte, s'hi combinen una sèrie d'interaccions de diversa naturalesa: correus electrònics, històries de vides al xat del Messenger i relats de vida a través del Google Documents. Aquesta aplicació de diferents maneres d'observar, participar i comunicar-se directament amb els participants permet la triangulació.

D'entre totes les tècniques seleccionades per a la recol-lecció de dades, cal diferenciar entre les observacionals com ara el diari de la investigadora del treball de camp, l'observació presencial concretada en les visites i l'observació virtual concretada en el seguiment de les plataformes digitals i les tècniques no observacionals com el qüestionari, l'entrevista, la història i el relat de vida. Per a la creació i el disseny del diari de camp s'han seguit les recomanacions de Latorre (2003) sobre la revisió contínua, les de Blaxter, Hughes \& Tight (2008: 63) i Vasilachis (2006: 136) que coincideixen a considerar-lo un registre clau per a la investigació, ja que anota el progrés, els sentiments, els pensaments, les pors, les preocupacions, les inseguretats i les intuïcions dia a dia, també explicita els canvis i les transformacions que acompanyen el treball des del moment que va començar i perfila el context de la investigació.

La proposta triada d'observació distingeix dues vessants: la presencial, que es materialitza en les visites i on els professors funcionen de mediadors, i la virtual, que comporta el seguiment de les plataformes digitals per la nostra part. S'hi parteix de les propostes d'observació qualitativa. La primera implica endinsar-se en profunditat 
en situacions socials i mantenir un paper de reflexió constant, on s'ha d'estar atent als detalls, successos i interaccions. La segona es concreta en l'observació de participació moderada, és a dir, aquella on els investigadors demanen aclariments com a observadors. Quant a la materialització d'aquesta observació, hi juguen un paper destacat les descripcions detallades i exhaustives juntament amb les notes de camp i els registres com proposa McKernan (I999: 80-84). Aquestes descripcions es fan, d'una banda, de les dotze visites als centres i, de l'altra, de l'observació virtual de les plataformes digitals que es duen a terme al llarg de cada avaluació.

El qüestionari és l'única tècnica quantitativa utilitzada durant el treball de camp i es fa cara a cara per assolir un índex de resposta superior. D'entre els enfocaments que Olivier Donnat (Lahire 2004: 6I) diferencia, aquesta investigació es decanta per l'enquesta que formula hipòtesis. Pel que fa al tipus de preguntes, a partir de les propostes de McKernan (I999: I45-I47) i Berganza \& Ruiz (2005: 190-I9I), el qüestionari dissenyat combina preguntes de resposta oberta i tancada. Per a l'anàlisi, s'hi fa servir el primer nivell, que Blaxter, Hughes \& Tight (2008: 232) anomenen estadística descriptiva, i que disposa de percentatges, mitjanes i rangs. Les entrevistes parteixen fonamentalment de la proposta d'Olaz (2008), ja que s'hi comparteix l'ús del guió memoritzat com a element vertebrador i de referència. El tipus d'entrevista, seguint la classificació de Mayntz (1975: 134-I35) citat per Olaz (2008: 27-30), és la intensiva o en profunditat, ja que s'hi pretén ampliar el coneixement sobre un problema mínimament estructurat. Finalment, les entrevistes s'hi organitzen en quatre fases: la fase del contacte inicial, on s'estableix el marc on transcorre l'entrevista, s'assenyala la importància de la seua contribució en la investigació i s'agraeix la col-laboració; l'obertura, on es formula la primera pregunta de manera genèrica en relació amb el tema que es tractà $\mathrm{i}$ altres preguntes obertes; el desenvolupament, que aconsegueix la màxima informació sobre el tema investigat i on es recondueix tantes vegades com és necessari a l'entrevistat sobre el tema a tractar i, finalment, la fase de tancament, on l'entrevistador fa una síntesi de les conclusions més importants.

A partir de la classificació de Pujadas (1992), la història de vida utilitzada és la de relats paral.lels, perquè superposa els relats autobiogràfics d'alumnes d'una mateixa classe. Aquesta tècnica permet la reconstrucció del sentit de determinats fets o de la pertinença a determinats grups o institucions socials i constitueix una mostra representativa de l'univers analitzat. Seguint la terminologia de Vasilachis (2006: 184-I94), la història de vida utilitzada té un disseny multivocal o polifònic que permet encreuar referències i relats de diferents persones, es fa amb persones comunes, l'eix temàtic 
seguit és una línia de vida i l'instrument que es fa servir és l'entrevista oberta. En el primer contacte amb els alumnes participants, la investigació opta per fer història de vida individual de cadascun d'ells, però en els següents es passa a la col-lectiva. Es realitzen a partir del xat del Messenger, perquè aquest sistema de comunicació virtual és més accessible als actors analitzats i genera més comoditat en l'entrevistat per parlar de si mateix; a més, permet realitzar històries de vida col-lectives i dóna una llibertat d'horaris per a les trobades.

L'ús del relat de vida té com a finalitat la reflexió social a partir d'un relat personal (Vasilachis 2006: I84-I94), es basa en la subjectivitat i en l'experiència de l'individu, ja que aquest ha de ser part de la societat que s'estudia. Les dades del relat de vida per a la investigació s'obtenen fonamentalment a través de l'ús de Google Documents: cada alumne seleccionat per a les històries de vida participa també, setmanalment, amb una entrada cronològica al document creat i dedicat al relat de vida, on conta en primera persona l'experiència com a individu que forma part de la societat que s'estudia. Finalment, una vegada completada la recol-lecció de dades i l'anàlisi a partir del grup de discussió i la triangulació, és possible construir uns indicadors qualitatius que permeten l'avaluació de les pràctiques lectores en diferents formats digitals.

En conclusió, el disseny de la investigació és el següent (taula I):

Taula I. Adaptació de disseny de casos múltiples de Vasilachis (2006: 228)

\begin{tabular}{|c|c|c|c|}
\hline $\begin{array}{l}\text { Nivell } \\
\text { de l'estudi }\end{array}$ & Dimensions delproblema & Fonts d'informació & Procediments i tècniques \\
\hline Context & $\begin{array}{l}\text { Curs escolar 20Io-20II } \\
\text { Picanya, L'Elianai València }\end{array}$ & $\begin{array}{l}\text { Mediadors de contacte } \\
\text { Internet }\end{array}$ & Entrevistes de presentació \\
\hline $\begin{array}{l}\text { Marc } \\
\text { institucional }\end{array}$ & $\begin{array}{l}\text { Centres escolars: Escola } \\
\text { Gavina 6è primària, Co- } \\
\text { legio Helios } 2 n \text { ESO i IES } \\
\text { Joanot Martorell } 4 \mathrm{t} \text { ESO }\end{array}$ & $\begin{array}{l}\text { Activitat real: I2 visites, } 3 \\
\text { plataformes, documents } \\
\text { dels centre i activitats }\end{array}$ & $\begin{array}{l}\text { Observació de participació } \\
\text { moderada }\end{array}$ \\
\hline \multirow{3}{*}{ Actors } & Professorat (mediador) & Testimonis & $\begin{array}{l}\text { Entrevistes en profunditat } \\
\text { i grup de discussió }\end{array}$ \\
\hline & Alumnat & Testimonis & $\begin{array}{l}\text { Qüestionaris, històries de } \\
\text { vida i relats de vida }\end{array}$ \\
\hline & Observador (investigador) & $\begin{array}{l}\text { Centre i plataformes } \\
\text { digitals }\end{array}$ & Diari i notes de camp \\
\hline
\end{tabular}




\section{EL PROCÉS DE LA INVESTIGACIÓ}

Aquest procés s'inicia i coincideix amb la pregunta inicial de la investigació acompanyada d'unes dades concretes prèviament planificades. L'objectiu general és analitzar la promoció de la lectura en el marc educatiu a través del web, el blog i el wiki. La investigació queda emmarcada en el curs escolar 20IO-20II, exactament des de l'i de setembre de 2010 fins al 30 de juny de 20II, i es realitza en l'estudi dels tres casos presentats en l'apartat anterior. Durant el treball de camp s'analitzen i s'avaluen les activitats de lectura i escriptura dutes a terme, explicades a través de la nostra observació, així com dels textos generats pel professorat i l'alumnat.

De l'objectiu general, se'n deriven tres d'específics. El primer, observar l'aplicació del web, el blog i el wiki per a la promoció de la lectura en l'aula a partir de tres casos concrets. Això significa descriure el context territorial on se situen les pràctiques concretes de lectura: el centre educatiu inserit en la seua realitat espaciotemporal, detallar les plataformes digitals utilitzades per a la posada en marxa de les pràctiques i els subjectes que s'hi involucren, i retratar els components centrals que articulen el projecte; els mediadors, els grups i els participants seleccionats. El segon objectiu específic és interpretar les aportacions de les plataformes; per tant, analitzar i avaluar les respostes dels mediadors, analitzar i interpretar la utilitat d'aquests tres casos reals a partir de les consideracions dels participants $i$ analitzar els textos creats pels alumnes a l'aula i introduïts a la plataforma. Finalment, el tercer objectiu és apropar exemples de pràctiques educatives de promoció de la lectura amb l'ús de les tecnologies a les persones interessades i valorar-ne els assoliments.

El procés de la investigació es va dissenyar en tres fases amb l'aplicació de les metodologies descrites en el punt anterior. En la primera fase, l'investigador observava les pràctiques investigades, amb una col-laboració moderada i activa dels professors que assolien el paper de mediadors al llarg de tot el treball de camp. Els actors s'estructuraren en tres grups: un primer grup format pels tres professors triats que feien el paper de mediadors de l'observació, membres participants en el grup de discussió i protagonistes de l'entrevista en profunditat. La varietat de temes i la complexitat del grup de discussió es representa en aquest gràfic (gràfic I): 


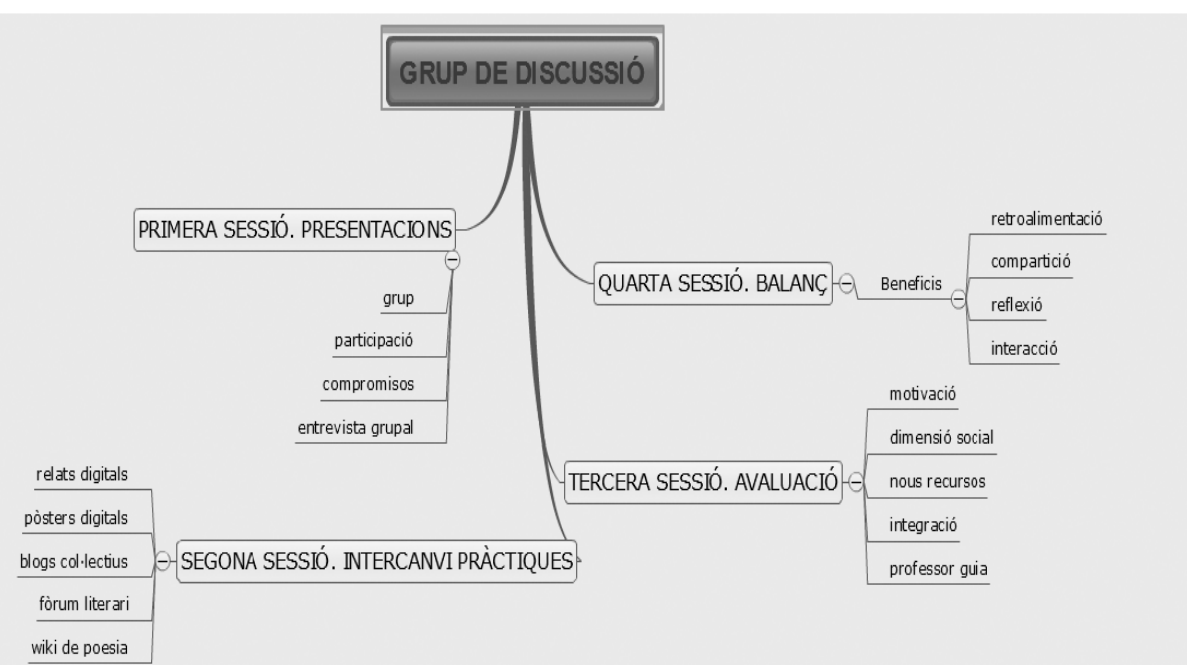

Gràfic I. Mapa conceptual de les sessions del grup de discussió

\section{Un exemple de les intervencions del professors a les sessions del grup de discussió} poden ser les transcripcions següents:

Ja no sabria viure sense l'ús tecnològic. Als alumnes els atrau moltíssim. I note que els alumnes estan escrivint $\mathrm{i}$ llegint més que mai amb moltes ganes i això abans no passava. Estan molt enganxats a llegir, a buscar, a investigar, a participar, a voler aprendre, a eixir per a poder explicar aquella pàgina. Açò és un hamet fantàstic (Albert Dasí).

Tots els alumnes quan entren a classe fan lectura de quinze minuts de biblioteca d'aula i, a partir d'ací, fan les recomanacions o fitxes de lectura al blog. I ara, als quinze minuts de lectura, incorpore tres alumnes rotatius que durant eixos quinze minuts lligen una llista de blogs (Evaristo Romaguera).

Lúltima cosa que he pogut comprovar objectivament és que els alumnes han llegit per a poder debatre i participar al forum de wiki. S'acaben de llegir la novel.la perquè és un acte social i han d'opinar davant de tots i no com l'examen, que és únicament davant del professor. Eixe és un benefici (Antoni de la Torre).

El segon grup el formava l'alumnat: d'una banda, la totalitat de la classe que realitzava el qüestionari que combina preguntes tancades i obertes; de l'altra, un petit grup que es presentaren voluntaris i que formaren el grup reduït que treballaren directament amb l'investigador de forma virtual. També fou el grup que, a través del xat del Messenger, construïren les històries de vida i, a partir del Google Documents, elaboraren el relat de vida. A continuació, reproduïm un fragment extret del xat del Messenger: 
Maite diu:

Però per què els alumnes prefereixen Internet que llapis i paper?

\section{Sandra diu:}

Perquè per a nosaltres és millor fer-ho a ordinador, a més ens posem música i fem altres coses mentre fem els treballs.

Xavi diu:

Pense que és més ràpid, senzill, entretingut i ordenat a ordinador, i més ràpid... A més, pots guardar còpies de seguretat, enviar-ho facilment, modificar quan vulgues.

\section{Sandra diu:}

Podem compartir el que fem i fer treballs junts alhora.

Xavi diu:

Podem aprendre coses dels altres, comparar, saber el que fem bé o mal, en què es pot millorar i pense que, fins i tot, pot arribar a motivar. El fet que un company puga veure el teu treball fa que almenys «te'l curres un poc», per demostrar que ho pots fer bé. Tampoc es tracta de guanyar els altres, que el teu siga més bo perquè el dels altres és pitjor, sinó intentar fer-ho bé i estar content amb el que fas. No sé si m’explique.

\section{Sandra diu:}

Que els altres vegen que saps fer-ho i que els agrade.

Finalment, l'últim grup estava format per la investigadora i moderadora del grup de discussió, que completava la informació que donava pas a la triangulació mitjançant les notes de camp i el diari del treball de camp. Un exemple n'és el fragment següent extret del diari de camp de la investigadora:

\section{8 de novembre}

Passe el dia a Colegio Helios, dine, visite la Biblioteca del Lunes, parle amb una bibliotecària voluntària i coordinadora d'un club de lectura, Raquel Pérez. Existeixen adolescents amb inquietuds lectores! Després assistisc al curs de formació sobre TIC a les classes de llengua. Fan un berenar de coques casolanes. Profit!

Durant la segona fase, es treballava amb el grup de discussió i la triangulació. L'anàlisi i la interpretació dels tres casos partia de les dades recollides durant l'estudi i arreplegades en diferents formats segons la seua naturalesa. Hi ha tres tipus de dades. En primer lloc, els documents en format paper, com qüestionaris que es passaren a la totalitat d'alumnes de les tres classes, el material facilitat pel centre a través de fotocòpies i tríptics, i els compromisos de participació signats pels participants de la investigació. En segon lloc, els documents sonors aconseguits a partir dels enregistraments que van 
ser transcrits de manera seleccionada a la investigació. En aquest grup s'hi afegiren les entrevistes en profunditat realitzades als tres professors, les reunions del grup de discussió $\mathrm{i}$ altres entrevistes dutes a terme a membres rellevants de la comunitat educativa. El tercer tipus de dades estava format pels documents publicats en xarxa, com ara les aportacions del relat de vida publicades al Google Documents, les històries de vida aconseguides a partir del xat del Messenger, guardades i convertides a format Word, i tota la redacció realitzada; des de les anotacions al diari fins a les notes de camp de les visites, passant per l'observació virtual de les plataformes.

Per classificar les dades, cada material es va identificar i classificar amb un lema, una data, l'actor que originava el document, el lloc i la forma de recollir la informació i, finalment, l'objectiu del material. Pel que fa a la naturalesa de la informació, les dades recollides van ser majoritàriament qualitatives; les úniques dades quantitatives s'obtingueren del qüestionari i per analitzar-les es calcularen les mitjanes i els percentatges, ja que l'objectiu del qüestionari en aquesta investigació era una estadística descriptiva i l'exploració de les relacions internes entre parells de variables.

D'altra banda i des d'una perspectiva qualitativa, l'anàlisi de les entrevistes i de les històries de vida, l'observació de les plataformes i les visites es va realitzar a partir de l'examen de les dades i de l'extracció de les similituds i diferències. Per aconseguir aquest propòsit en les entrevistes i les històries de vida, en primer lloc, s'identificà la procedència del document amb un informe que incloïa les dades personals. Després se subratllaren les aportacions que es consideraren més rellevants de cadascun dels documents i s'anotaren creant unitats de significat i s'hi s'inclogueren etiquetes classificatòries. Finalment, es contrastaren les respostes de les entrevistes per unitats i s'extragueren les similituds i les diferències, es buscaren temàtiques comunes i se'n féu un resum, que és el resultat de tot el procés previ d'anàlisi i interpretació.

En aquesta segona fase és important la diversitat de factors que tenen en compte a l'hora de dur a terme l'anàlisi, a banda dels formats, la procedència i la naturalesa dels documents que s'inclouen i que ja han estat explicats. Aquests factors pertanyen a l'anàlisi del discurs i s'estructuren en tres grups. El primer grup el formaren els idiomes que es van fer servir: la llengua vehicular és predominantment el català $i$ minoritàriament el castellà, ja que la llengua emprada i els documents estaven escrits exclusivament en català, els dels professors també. Únicament dos alumnes van fer servir el castellà per expressar-se en algun moment de la història de vida, així com els documents que faciliten el centre del Colegio Helios. Al segon grup es diferenciaren dos tipus de canals: l'oral i l'escrit. L'oral s'utilitzava al grup de discussió i a les 
entrevistes, les converses s'enregistraren i, posteriorment, es transcrigueren. A l'últim grup s'inclogueren la varietat de registres. El registre utilitzat va ser l'estàndard i, en algun moment determinat, es va fer servir un registre especialitzat de les tecnologies, sobretot en parlar de l'alfabetització digital al grup de discussió.

Durant les converses mantingudes entre la investigadora i l'alumnat al xat del Messenger, però, s'observà en determinades ocasions l'ús del registre col-loquial per un motiu doble: d'una banda, el fet que ells utilitzaren aquesta eina com a instrument de socialització i no com un recurs acadèmic, amb la qual cosa van fer servir sovint un registre familiar; però sobretot perquè es buscava una estratègia comunicativa que els fera sentir còmodes per poder crear un espai que facilitara l'obtenció d'informació. Així doncs, s'hi van utilitzar emoticones per representar els sentiments amb un registre similar al que ells utilitzaven i les preguntes s'hi van formular de manera que els estimularen i els motivaren a proporcionar les dades que la investigació necessitava.

La tercera fase es va centrar en l'avaluació. A partir dels resultats de l'anàlisi i la interpretació de les activitats analitzades durant la investigació per a la triangulació, s'extragueren uns indicadors d'avaluació que eren aplicables a qualsevol pràctica lectora a l'aula amb l'ús de les tecnologies. Aquests indicadors són la mesura dels resultats de la investigació per comunicar-los a la comunitat (Lluch 2013: $\$ 7.6$ ).

Com a guia per extraure els indicadors d'avaluació, es va plantejar una classificació que partia de les tres perspectives de la triangulació d'informació. La primera perspectiva era la del professorat i el primer bloc d'indicadors estava enfocat als objectius i les competències que es volien aconseguir al llarg del curs escolar, és a dir, a l'aprenentatge que els professors consideraven que els alumnes havien de fer per a l'assignatura. Cal subratllar que ací es deixaren a banda els diferents continguts d'etapa del currículum pel que feia a l'assignatura de llengua i se centraren en les competències bàsiques, les quals prenien especial protagonisme arran de la implantació de la LOE. La segona perspectiva era la de l'alumnat i el segon bloc d'indicadors tenia la base en l'interès i la motivació que els alumnes mostraven en l'assignatura o en el projecte pel fet d'utilitzar aquestes eines. Finalment, la tercera perspectiva se centrava en la plataforma a través de les nostres percepcions i el tercer bloc indicava les possibilitats $i$ el rendiment que s'observava en el funcionament de la plataforma.

L'elaboració i la concreció dels quinze indicadors d'avaluació que hem construït per a aquesta investigació provenen de l'anàlisi de les intervencions dels participants $\mathrm{i}$ de les consideracions de la investigadora contrastades conjuntament amb documents de referència que serveixen d'argument d'autoritat. Aquests documents són 
principalment els decrets que estableixen el currículum d'Educació Primària i Secundària Obligatòria, la investigació de Henry Jenkins (2006), l'obra recopilatòria de J. J. Haro (20I0) i l'informe de Margaix (2008). La taula 2 resumeix el disseny propi de classificació dels indicadors d'avaluació:

Taula 2. Classificació de disseny propi dels indicadors d'avaluació

\begin{tabular}{|c|c|}
\hline Perspectiva de la triangulació & Indicadors d'avaluació \\
\hline Professorat & $\begin{array}{l}\text { Objectius i competències: } \\
\text { - Lectoescriptura i cultura } \\
\text { - Alfabetització digital } \\
\text { - Aprendre a aprendre } \\
\text { - Autonomia i iniciativa } \\
\text { - Fer ciutadans }\end{array}$ \\
\hline Alumnat & $\begin{array}{l}\text { Motivació: } \\
\text { — Interacció oberta } \\
\text { — Coneixements previs } \\
\text { — Protagonisme } \\
\text { — Utilitat } \\
\text { — Possibilitat d'elecció }\end{array}$ \\
\hline Observadora de la plataforma & $\begin{array}{l}\text { Possibilitats: } \\
\text { — Comunicació } \\
\text { — Diversitat } \\
\text { — Periodicitat } \\
\text { — Avaluació } \\
\text { — Accessibilitat }\end{array}$ \\
\hline
\end{tabular}

\section{ELS RESULTATS}

Les dades evidencien empíricament, mitjançant l'objectivació d'aquestes pràctiques, que l'ús de les plataformes utilitzades en els casos que ocupen la investigació (el wiki, el blog d'aula i el web) és molt beneficiós en el treball de la lectura. En els tres casos analitzats, i en la línia iniciada per Jenkins (2006), les formes de lectura i escriptura utilitzant els mitjans digitals s'entenen com una expansió i no com una substitució de les formes tradicionals; a més, els estudiants les valoren com un fort incentiu per a llegir i escriure.

El gràfic 2 mostra la relació que els estudiants, que participen en la investigació, tenen amb la lectura $\mathrm{i}$ internet: 


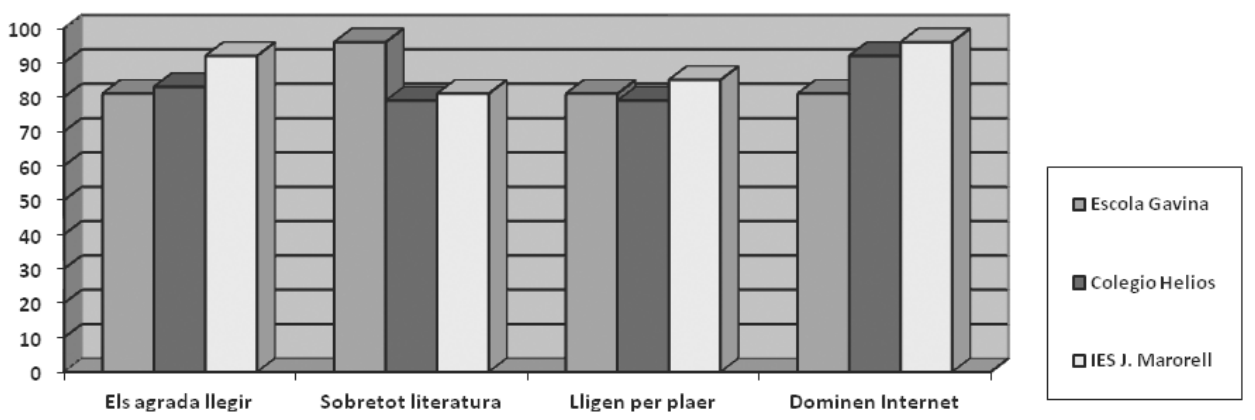

Gràfic 2. Respostes de l'alumne

\section{I SOBRE ELS ESTUDIANTS}

Els resultats de la investigació sobre la resposta dels estudiants han demostrat que la motivació i l'interès que desperta en l'alumnat l'ús de les tecnologies en la promoció de la lectura prové de: en primer lloc, els alumnes estan familiaritzats amb la cultura tecnològica i, per tant, les pràctiques els resulten més divertides, se senten més còmodes i hi participen més. No obstant això, l'alumnat sempre és conscient que es troba en l'àmbit acadèmic i en gran part assumeix, com assenyala Margaix (2008), que cada xarxa social crea una cultura i una manera de relacionar-s'hi, té una missió concreta i un públic determinat.

Però més enllà de la comoditat i del divertiment, la investigació mostra altres dades força interessants en les respostes dels estudiants. Per exemple, ells valoren positivament el fet que les plataformes trenquen els murs de l'aula, permeten dur el treball més enllà i comunicar-se amb altres actors socials. D'aquesta manera, les plataformes virtuals permeten transformar les activitats escolars en pràctiques de comunicació reals i la lectura individual, en lectura social i compartida. Una altra motivació derivada ha estat que l'alumnat fa un aprenentatge útil i pràctic, ja que posteriorment pot aplicar-lo al seu entorn acadèmic, professional o, fins i tot, personal.

Però per poder usar les plataformes de manera àgil i ràpida són necessaris uns mínims coneixements previs. Els resultats mostren com l'alumnat valora el fet de disposar d'aquests sabers que l'escola tradicionalment no avalua ni ensenya i que, 
per tant, adquireix fora de l'àmbit acadèmic. Els casos analitzats possibiliten que puguen activar, demostrar i compartir els coneixements adquirits a casa més enllà del llibre escolar i, òbviament, la satisfacció expressada per l'alumnat és gran.

Ara bé, el fet de voler demostrar aquests coneixements implica alhora ensenyar-los a la resta del grup, mostrar-los, exhibir-se, amb la qual cosa l'esforç és més gran i també els resultats. És el que Jenkins (2006) anomena "cultura participativa» i Haro (20IO) "participació col-lectiva». Els estudiants han valorat com a molt motivador el fet de poder ensenyar i aprendre els uns dels altres, però també els resultats han evidenciat que no necessàriament els que tenen aquests coneixements són els que obtenen millors resultats acadèmics.

Haro (20I0) destaca el reconeixement del treball aliè, no apropiant-se’l sinó edificant i construint a partir d'aquest. Les plataformes virtuals han produït a l'aula un canvi de rols entre els grups habituals de l'alumnat, perquè no necessàriament aquells que més coneixements de l'assignatura tenen són els que controlen l'ús de les tecnologies i a la inversa, de manera que el protagonisme a l'aula s'anivella i l'intercanvi horitzontal de coneixements entre el grup esdevé una necessitat. Com a conseqüència, els espais de comunicació que De la Torre, Romaguera i La Gavina han creat permeten atendre la diversitat i l'intercanvi. No hem d'oblidar que la major possibilitat que ofereixen les plataformes és el fet de poder compartir informació, de treballar conjuntament i estar en contacte, la qual cosa implica aprendre de la resta de la gent, comparar aprenentatges i, fins i tot, millorar-los. Jenkins (2006) defineix aquest aprenentatge d'explotar el potencial de la comunicació en les xarxes com a «intel-ligència col-lectiva».

L'últim aspecte motivador identificat entre els estudiants és el fet que poden elegir entre fer una activitat o una altra, entre utilitzar una eina concreta o una altra, entre triar una determinada lectura o una altra, és a dir, la possibilitat d'elecció en diferents nivells.

\subsection{SOBRE LA LECTURA}

Els resultats de la investigació han demostrat com el tipus de pràctica realitzada als centres ha ampliat la lectura als diferents tipus, llenguatges i suports, més enllà del paper o del llibre. En els tres casos analitzats la lectura no s'entén sols com a literària o «lectura d'oci», sinó que inclou documents lligats a tots els àmbits de coneixement i en especial en els processos de cerca i ús de la informació. 
El concepte de material escolar s'hi amplia i, amb aquest, l'accés als textos de lectura. Tradicionalment, l'ús d'un únic llibre de text ha provocat una estandardització dels documents que llegien i de les activitats que realitzaven els estudiants, per tant, limitava les oportunitats dels alumnes d'incorporar-se a una cultura escrita (Díaz Argüero 2008).

En definitiva, els casos mostren una ampliació i diversificació de textos, formats i, per tant, del concepte d'alfabetització amb una clara coexistència del llibre de text amb altres recursos didàctics.

\section{$4 \cdot 3$ SOBRE ELS DOCENTS}

Tot i que els tres centres on tingueren lloc les pràctiques analitzades representen contextos sociolingüístics ben diferents, tots tres coincideixen en tres fets importants sobre el paper del professorat: l'alta valoració que els estudiants van fer de la pràctica i del professorat, el desig que manifestaren que la resta del treball escolar seguira una pauta similar i que les pràctiques s'hi desenvoluparen al marge de la legislació valenciana, per tant, es van realitzar per la voluntat personal i l'entusiasme dels professors responsables, i van ser la conseqüència d'iniciatives individuals.

Però hi ha una altra dada significativa i que mostra per on ha d'anar no només la tasca del professorat sinó també la formació dels futurs docents. La investigació ha mostrat com el paper del professorat canvia notablement en aquests contextos sobretot perquè els textos que els professors generen sobre la creació dels alumnes justifiquen i il.lustren el paper de guia del professorat. Aquest és un canvi significatiu de mentalitat en l'àmbit educatiu: en aquestes pràctiques el professorat canvia de ser una figura relativament impositiva a tenir una funció orientadora integrada en el grup, paper que demana i possibilita les plataformes virtuals utilitzades. Valorem que aquesta disposició del professorat ha tingut un paper important en la reducció del fracàs escolar dels grups analitzats.

\subsection{SOBRE LES PLATAFORMES}

Pel que fa a les plataformes, la investigació destaca com a punt positiu la interdisciplinarietat i la diversitat de formats que poden assolir les diferents propostes de treball. És a dir, algunes de les pràctiques de lectura proposades als estudiants es realitzen des de diverses disciplines i amb la utilització de formats diferents. Aquesta 
diversitat permet, a més, informar els estudiants de la periodicitat del treball que han de realitzar com una mena de cronograma, informar-los del que ja han fet, com un dietari, i també marcar la continuïtat i el ritme. La plataforma que aglutina les eines i els formats controla $i$ indica si s'han presentat els treballs en la data establerta o quan i quantes vegades hi han accedit per a revisar-los. Així mateix, els actors han destacat com a molt positiu la capacitat d'avaluació de la plataforma i d'aparador per resseguir els aprenentatges que s'han fet des del principi fins al final. A través de la plataforma, es mostra el procés a més dels resultats i, fins i tot, es poden seleccionar els millors treballs dels alumnes i oferir-los públicament en cadascuna de les activitats. Finalment, hi ha la possibilitat de guardar, recuperar, ordenar, modificar i accedir en qualsevol moment i des de qualsevol ordinador a la informació sol-licitada.

Aquestes plataformes han estat força útils i gairebé imprescindibles durant la investigació. Com s'ha explicat a l'apartat 2 , les diferents plataformes virtuals han estat presents en la investigació i han sigut imprescindibles en totes les fases, sobretot en la recollida de dades i a l'hora de compartir els resultats amb els diferents actors. Així doncs, l'anàlisi de les dades recollides mostren que va ser un èxit compartir amb el professorat tots els documents generats al llarg del procés investigador a través del Google Documents. Com a mediadors, coneixien en tot moment les aportacions dels alumnes $\mathrm{i}$, fins i tot, les anàlisis de les intervencions i de les activitats que es van dur a terme, amb la retroalimentació que tot aquest procés permet. Aquesta els permetia introduir comentaris, preguntes, dubtes o certeses a partir de la seua mirada i indicar quines modificacions introduïen en la seua pràctica docent a partir de la investigació. Els dos aspectes més valorats pels professors ha estat la possibilitat de conèixer les opinions dels alumnes (a partir de les intervencions i de les dades resultats de l'anàlisi) deslligades del condicionament que suposa la figura del professor. L'altre, la possibilitat de conèixer de manera exhaustiva unes altres iniciatives de les quals poder aprendre per desenvolupar la seua feina, ja que els tres professors tenien accés a tota la informació.

\section{DISCUSSIÓ I CONCLUSIONS}

Al final d'una investigació com aquesta sobre pràctiques de lectura, el repte de l'investigador és poder donar compte d'una pràctica de lectura concreta amb l'ús de metodologies explícites i acordades que permeten conèixer-la, distingir-la, examinar-la i avaluar-la. En l'apartat anterior, hem referit alguns dels principals resultats 
de la investigació. Òbviament, la principal conclusió és que l'ús de plataformes i eines virtuals a l'hora de dissenyar el treball sobre i amb la lectura a l'aula és no sols recomanable sinó que en podríem dir imprescindible. Els tres casos analitzats mostren la necessitat d'una reformulació del paper de la lectura en general i en català en particular en la institució escolar, una ampliació del concepte d'alfabetització i de la incorporació del món de la tecnologia als materials didàctics.

Tot i que les diferents investigacions realitzades ja mostraven aquestes conclusions, malauradament encara una part dels professionals lligats a les humanitats, i entre aquests encara massa docents, considera la lectura i l'ús de la tecnologia conceptes excloents i enfrontats.

Investigacions que analitzen espais on es parla de la lectura i espais virtuals mostren resultats que també cal tenir en compte en el disseny de pràctiques de lectura. Per exemple, la investigació coordinada per Martín Barbero (2OII) on s’analitzen pràctiques de lectura diversificades però amb un punt en comú: la transformació d'aquestes en experiències de vida i la comunicació de la lectura a través de plataformes virtuals com a eix fonamental; Marsh (20II) analitza com nens entre cinc i onze anys construeixen webs socials en un entorn virtual creat pel Club Penguin. Garcia Canclini, Cruces \& Urteaga Castro Pozo (20I2), com els joves es transformen en trendsetter que lideren estils en tots els camps culturals, incloent-hi, òbviament, el de l'edició i la creació de textos literaris.

Però la investigació sobre els espais virtuals que utilitzen els adolescents per parlar de lectura és molt recent. Lluch \& Acosta (20I2) analitzen els fòrums de Laura Gallego, les característiques d'aquest espai virtual creat per l'autora i que congrega centenars de joves; Sánchez, Lluch \& Del Río (2013) presenten i analitzen els espais virtuals que l'editorial SM ha creat per al Reto Delirium i les converses que s'hi generen entre els adolescents sobre els llibres; aquesta iniciativa viral es va crear per a la promoció de la novel.la de Lauren Oliver, Delirium, entre els mesos de gener a març de 20 II.

Investigacions com aquesta volen contribuir, d'una banda, a l'aplicació de les TIC a les maneres de treballar la promoció de la lectura i, de l'altra, a destruir un dels tòpics actuals més arrelats pel que fa a la lectura, on s'afirma que la lectura es veu amenaçada per «les noves tecnologies» (Millán 2008: 209-219). A més, permeten, des de les dades que ofereix una investigació, i no des de la intuïció o la pràctica no contrastada, oferir informació per poder construir un protocol futur sobre les pràctiques de lectura a l'aula. 
Làmbit de la filologia ha d'obrir-se necessàriament a estudis lligats a la realitat on la consideració de la lectura va més enllà del paper o del text i es transforma en pràctiques d'un centre educatiu que generen espais on adolescents parlen de lectura, d'autors i de textos. Des d'aquesta perspectiva, proposem finalment entendre la lectura com a participació i com Jenkins (2006: 8): "we focus in this paper on the concept of participatory cultures rather than on interactive technologies. Interactivity is a property of the technology, while participation is a property of culture».

\section{Maite Monar van Vliet Universitat de València / Professora de Valencià. Llengua i Literatura maitemvv@gmail.com \\ Gemma Lluch Universitat de València / ERI Lectura gemma.lluch@uv.es}

\section{REFERÈNCIES BIBLIOGRÀFIQUES}

Berganza, R. \& J. A. Ruiz (2005) Investigar en comunicación. Guía práctica de métodos y técnicas de investigación social en comunicación, Madrid, McGraw-Hill I Interamericana de España.

Blaxter, L., C. Hughes \& M. Tight (2008) Cómo se investiga, Barcelona, Graó.

Buendía, L., P. Colás \& F. Hernández (1998) Métodos de Investigación en Psicopedagogía, Madrid, McGraw-Hill / Interamericana de España.

Callejo, J. (200I) El grupo de discusión: introducción a una práctica de investigación, Ariel, Barcelona.

Coller, X. (2005) Estudio de casos, Madrid, CIS.

Díaz Argüero, C. (2008) «Libros de texto y bibliotecas: un libro o muchos materiales", dins E. Bonilla, D. Goldin \& R. Salaberria, Bibliotecas y escuelas. Retos y posibilidades en la sociedad del conocimiento, Barcelona, Océano, pp. I85-208.

«Decret II2/2007, de 20 de juliol, del Consell, pel qual s'establix el currículum de l'Educació Secundària Obligatòria a la Comunitat Valenciana», Diari Oficial de la Comunitat Valenciana (24 juliol 2007), núm. 5562, pp. 30402-30587.

Denzin, N. K. (2003) The landscape of qualitative research. Theories and issues, Califòrnia, Sage Publications. 
García Canclini, N., F. Cruces \& M. Urteaga Castro Pozo, coords. (20i2) Jóvenes, culturas urbanas y redes digitales. Prácticas emergentes en las artes, las editoriales y la música, Madrid, Fundación Telefónica / Ariel.

Haro Ollé, J. J. (2010) Redes sociales para la educación, Madrid, Anaya.

Hammersley, M. \& P. Atkinson (1994) Etnografía: métodos de investigación, Barcelona, Paidós.

Hernández, R., C. Fernández \& P. Baptista (2006) Metodología de la investigación, Mèxic, McGraw-Hill Interamericana.

Hymes, Dell H. (1977) Foundations in Sociolinguistics, Philadelphia, University of Pennsylvania Press.

Hine, C. (2004) Etnografia virtual, Barcelona, UOC.

Jenkins, H. (2006) Confronting the Challenges of Participatory Culture: Media Education for the 2Ist Century, Barcelona, John D. and Catherine T. MacArthur Foundation.

Lahire, B., coord. (2004) Sociología de la lectura, Barcelona, Gedisa Editorial.

Latorre, A. (2003) La investigación-acción. Conocer y cambiar la práctica educativa, Barcelona, Graó.

LLUCH, G. (20I3) La lectura en català per a infants $i$ adolescents. Història, investigació $i$ politiques, València/Barcelona, Institut Interuniversitari de Filologia Valenciana I Publicacions de l'Abadia de Montserrat.

Lluch, G. \& M. Acosta (2OI2) «Conversaciones sobre lecturas en la Web 2.0: el caso de Laura Gallego. Análisis discursivo de conversaciones virtuales entre adolescentes», dins J. Díaz Armas (ed.), Lecturas para el nuevo siglo: formación receptora y lector hipertextual, La Laguna, Servicio de Publicaciones de la Universidad de La Laguna.

Marsh, J. (2OII) «Young children's literacy practices in a virtual world: Establishing an online interaction order», Reading Research Quarterly, 46 (2), pp. IOI-II8.

Margaix, D. (2008) Informe APEI sobre web social, Gijón, Asociación Profesional de Especialistas en Información [<http://eprints.rclis.org/bitstream/I0760/12506/I/ informeapeiwebsocial.pdf>, data de consulta: 20 de desembre de 20II.]

Martín-Barbero, J. \& G. Lluch (2OII) Lectura, escritura y desarrollo en la sociedad de la información, Bogotà, Cerlalc/Unesco.

McKernan, J. (1999) Investigación-acción y curriculum, Madrid, Ediciones Morata.

Millán, J. A., coord. (2008) La lectura en España. Informe 2008. Leer para aprender, Madrid, FGSR i Federación de Gremios de Editores de España. [<http://www. lalectura.es/2008/informe2008.pdf $>$, data de consulta: 20 de desembre de 20II.] 
Monar Van Vliet, M. (2OI2a) "Promoción de la lectura en el marco educativo», Revista OCNOS, 8, pp. 67-74. [<http://www.revista.uclm.es/index.php/ocnos/ article/view/203/183>.]

- (20I2b) Promoció de la lectura en el marc educatiu, València, Roderic. Universitat de València. [Tesi doctoral: <http://roderic.uv.es/bitstream/handle/I0550/25190/ tesis.pdf?sequence $=3>$.]

Olaz Capitán, A. (2008) La entrevista en profundidad. Justificación metodológica y guia de actuación práctica, Oviedo, Septem Ediciones SL.

Pujadas, J. J. (1992) El método biográfico: el uso de las historias de vida en las ciencias sociales, Madrid, CIS.

Rodríguez Ruiz, O. (2005, núm. 3I). «La Triangulación como Estrategia de Investigación en Ciencias Sociales». Revista Madri+d, 3I: La I+D que tenemos, [<http:// www.madrimasd.org/revista/revistazi/tribuna/tribuna2.asp >, data de consulta: 3 d'octubre de 20Io.]

Rojas, B. (20Io) Investigación Cualitativa, Caracas/Veneçuela, FEDUPEL.

SÁnchez, S., G. Lluch \& T. Del Río (20I3): «La lectura en la web 2.o. Estudio de caso: Los blogs en el Reto Delirium», @tic. Revista d'innovació educativa, Io, València, Universitat de València, pp. 75-84.

TAYlor, S. J. \& R. Bogdan (1996) Introducción a los métodos cualitativos de investigación, Barcelona, Paidós.

Vasilachis de Gialdino, I. (2006) Estrategias de investigación cualitativa, Barcelona, Gedisa. 